\title{
Urgences
}

\section{Petits fruits de saisons (illustrations de David Carles)}

\section{Marie-Andrée Massicotte}

Numéro 8, 4e trimestre 1983

Littérature jeunesse

URI : https://id.erudit.org/iderudit/025116ar

DOI : https://doi.org/10.7202/025116ar

Aller au sommaire du numéro

Éditeur(s)

Urgences

ISSN

0226-9554 (imprimé)

1927-3924 (numérique)

Découvrir la revue

Citer ce document

Massicotte, M.-A. (1983). Petits fruits de saisons (illustrations de David Carles).

Urgences, (8), 27-33. https://doi.org/10.7202/025116ar d'utilisation que vous pouvez consulter en ligne.

https://apropos.erudit.org/fr/usagers/politique-dutilisation/ 


\section{MARIE-ANDRÉE MASSICOTTE}

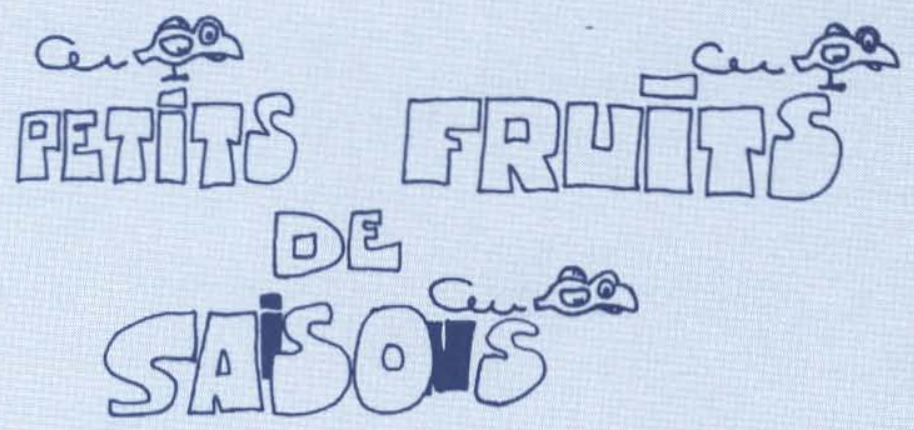

(illustrations: David Carles) 
A AURELIA

QUAND L'ODEUR DU SOUVENIR REMONTE LE LIT DU COURANT

QUE LE VENT TE SOUFFLE DE L'AUTRE CÔTÉ DE LA GRANDE MARE SALÉE

QUE LA COULEUR DU TEMPS SE TEINTE DES NUANCES DE CET ÉTÉ-LÀ

LA PETITE VOIX POINTUE CHANTONNE... 


\section{À I'AUTOMNE}

TOUT AU BOUT TOUT AU BOUT DU VOYAGE

JE REPRENDRAI LA MER... 


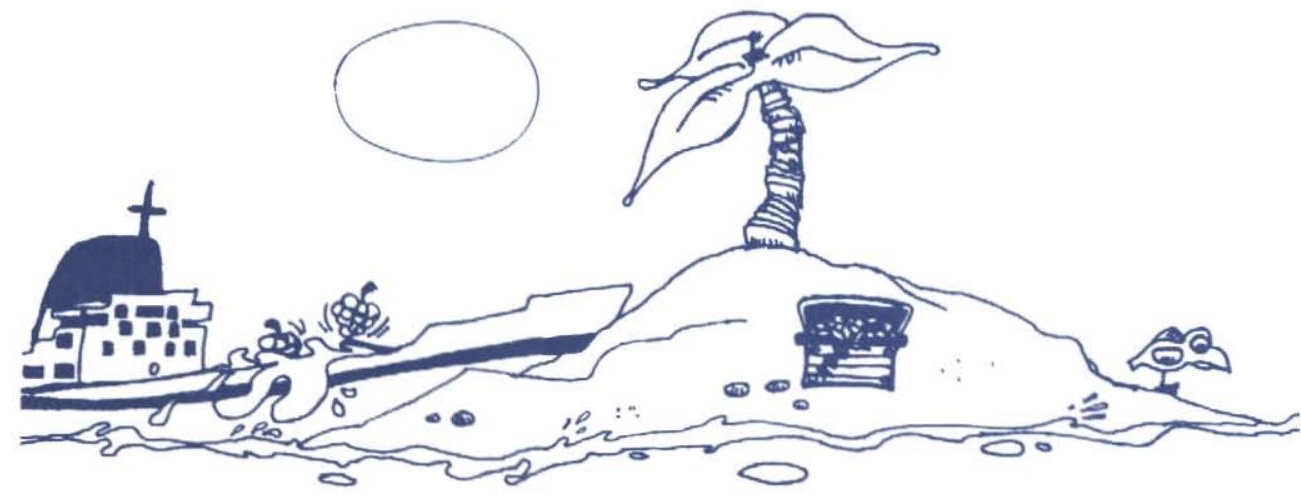

AVEC TOUS LES CAILLOUX BLANCS BRASSÉS PAR LES MARÉES

LE SEL ENTRE LES DENTS LES AGATHES BIEN LĖCHÉES

ET TOUS LES TRÉSORS DES ÎLES PERDUES DÉTERRÉS

POUR VOGUER SUR LES MERS JE T'ACHĖTERAI UN GRAND PÉTROLIER

AUX SOUTES ROUGES DU JUS DE TOUTES LES FRAMBOISES

GLANÉES DANS LE SECRET DES PETITS BONHEURS INVENTÉS

POUR CUEILLIR LE FOU RIRE AU FOUILLIS DES CHEMINS CREUX

ET FAIRE DURER L'ÉTÉ... 


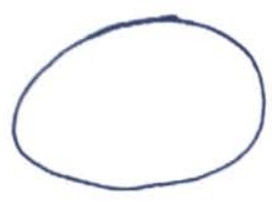

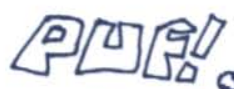

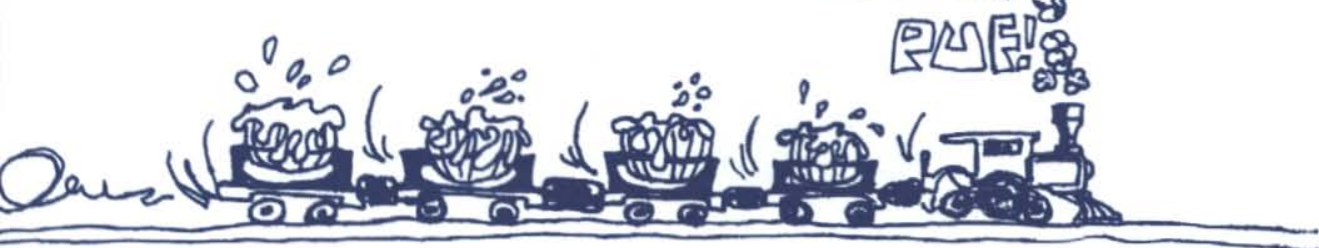

TOUT AU LONG TOUT AU LONG DU VOYAGE

DANS UN GRAND ENVOL DE CRIS ET DE CHANTS

LES FUITES DU SILLAGE NOURRIRONT LES OISEAUX ÉBOURIFFÉS

JE VIENDRAI CHAQUE ÉTÉ GOŨTER LE JUS DES CERISES

DANS LES BEAUX GRANDS VERRES DES TULIPES ÉTOILÉES

JE RAMĖMERAI DANS DES WAGONS-CITERNES

TOUT LE JUS DES RAISINS QUI AURONT PU NAITTRE... 

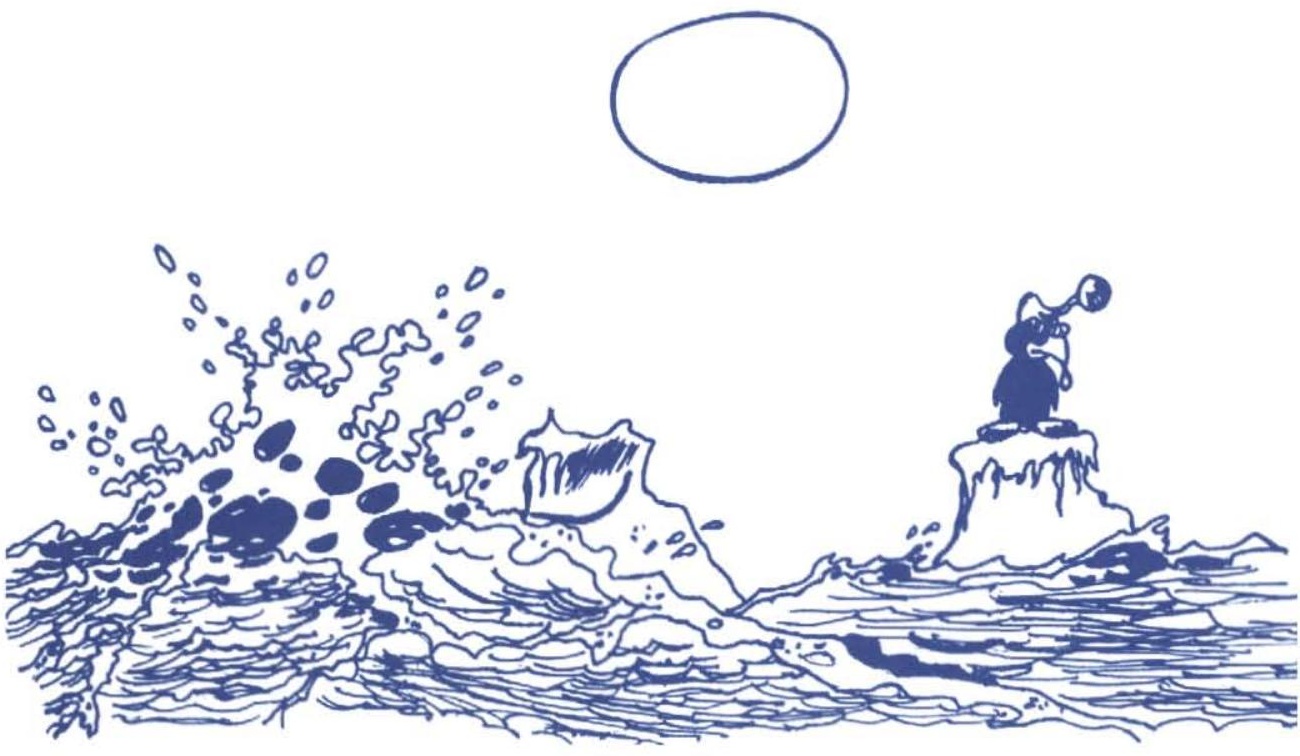

TOUT AU LONG TOUT AU LONG DU VOYAGE SE MÊLERONT EN BRASSANT DANS LES CALES TOUS LES PARFUMS ET LES FRUITS DE L'ÉTÉ ET LES JUS EN SAVANT MÉLANGE POUR LES JOURS FROIDS OU TOUT SEMBLE FIGÉ... 
DANS LES FLÛTES DU VENT

DANS LA COULEUR DU TEMPS

PARFOIS

CARILLONNENT TES HUIT ANS 